\title{
LA PUBLICIDAD EN EL NUEVO SISTEMA PROCESAL PENAL Y LOS MEDIOS DE COMUNICACIÓN SOCIAL
}

\author{
Miguel Otero Lathrop \\ Profesor Titular de Derecho Procesal \\ Universidad de Chile
}

La publicidad en el nuevo sistema procesal penal es un tema bastante complejo, por cuanto en la aplicación de este principio inciden diversos preceptos constitucionales y normas legales. En efecto, dentro de las garantías constitucionales involucradas se encuentran el derecho al debido proceso, la privacidad y el derecho a informar libremente y sin censura previa, las cuales presentan facetas que pueden aparecer como contradictorias y crear conflictos de precedencia.

En otro aspecto, hay que distinguir claramente la publicidad en el juicio penal oral y en los procedimientos ante el juez de garantía, que son estrictamente jurisdiccionales, de las actuaciones propias del Ministerio Público, que son absolutamente administrativas en la fase investigativa y actos jurídicos procesales en el proceso penal.

A objeto de abordar el tema, lo hemos dividido en distintos capítulos, para su mejor comprensión y análisis:

\section{IMPORTANCIA DEL PRINCIPIO DE LA PUBLICIDAD, TANTO EN LO JURISDICCIONAL COMO EN LO ADMINISTRATIVO.}

La existencia y la observancia del principio de publicidad son imperativos ineludibles para controlar real y eficazmente el cumplimiento de las funciones del Ministerio Público y del Poder Judicial, como también para garantizar la existencia del Estado de Derecho, la observancia de la igualdad en el trato por parte de la autoridad y el derecho a un debido proceso.

a) Existencia del Estado de Derecho.

Esta está determinada por la observancia de lo dispuesto en los artículos $6^{\circ}$ y $7^{\circ}$ de la CPR. Esto es, que la ley es obligatoria para todos los habitantes de la República y que, quien la infrinja, cualesquiera sea su estirpe, sexo, estado, condición y dignidad, debe ser debidamente sancionado e indemnizar los perjuicios que tal proceder haya causado. 
La observancia de estos principios permite, además, una adecuada y efectiva fiscalización y control del accionar jurisdiccional y el del Ministerio Público, no sólo por parte los medios de comunicación social sino también por los encargados de ejercer el control de legalidad y juridicidad de la actuación pública (v. gr. partidos políticos, Congreso Nacional, etc.).

b) La igualdad en el trato por parte de la autoridad

El cumplimiento de esta obligación constitucional para toda autoridad pública, únicamente se puede controlar y comprobar mediante la publicidad de sus actos. Sin publicidad, se puede cometer toda clase de arbitrariedades y discriminaciones - sin que ello se sepa - violándose así impunemente esta garantía constitucional.

No basta la igualdad ante la ley. Esta sólo se materializa si el trato es igualitario. Así se desprende de las siguientes conclusiones consignadas en las Actas de la Comisión Constituyente de la Constitución de 1980:

"El señor Silva Bascuñán: en primer lugar, está la norma general de que no sólo en la formulación doctrinaria y abstracta y de la norma positiva debe haber igualdad de los ciudadanos ante la ley, sino que después, en todos los órganos de la Constitución y para todas las personas que viven en la sociedad política, en la práctica de esa norma ya promulgada debe haber real igualdad en el ejercicio de todos esos derechos".

"El señor Ortúzar (Presidente) agrega que la igualdad ante la ley significa que no puede dictarse una ley que establezca discriminaciones con respecto a los habitantes o a los ciudadanos; pero esas discriminaciones pueden producirse en la aplicación de la ley, sea por los organismos administrativos llamados a aplicarla, sea incluso por los propios tribunales de justicia. Entonces, ése es el concepto, ésa es la distinción: una cosa es que la ley sea igual para todos, pero otra cosa es que su aplicación sea igual para todos"1.

c) Derecho a un debido proceso

La Constitución Política no enumera cuales son los elementos de un justo y racional procedimiento. Sin embargo, en la Comisión Constituyente se señalaron, a modo ejemplar, algunos principios básicos que todo procedimiento debe contemplar para estimar que cumple con los requisitos de ser justo y racional ${ }^{2}$. Al efecto, el comisionado Sr. Diez expresó: "En este debate, en que toda la Comisión está de acuerdo, en que las normas racionales y justas de un debido proceso deben contemplar

\footnotetext{
${ }^{1}$ Actas de la Comisión Constituyente, sesión 100, celebrada el 9 de enero de 1975, p. 25

${ }^{2}$ Ver Actas de la Comisión Constituyente, especialmente, las sesiones $100^{2}, 101^{2}$ y $103^{2}$
} 
la posibilidad de tener conocimiento de la acción, de ser defendido, de poder rendir pruebas, de tener recursos cuando corresponda, enriquece el concepto de racional y juston' 3 .

\section{DERECHOS CONSTITUCIONALES APLICABLES}

Establecida la importancia del principio de la publicidad, tanto en el aspecto jurisdiccional como administrativo, nos corresponde analizar las disposiciones constitucionales y legales que, de una u otra forma, inciden en su extensión y aplicación.

\section{A.- EL DERECHO A PRIVACIDAD, A LA HONRA Y AL HONOR}

El artículo 19 de la CPR, garantiza:

"No 4: El respeto y protección a la vida privada y pública y a la honra de la persona y de su familia".

"La infracción de este precepto, cometida a través de un medio de comunicación social, y que consistiere en la imputación de un hecho o acto falso, o que cause injustificadamente daño o descrédito a una persona o a su familia, será constitutiva de delito y tendrá la sanción que determina la ley. Con todo, el medio de comunicación social podrá excepcionarse probando ante el Tribunal correspondiente la verdad de la imputación, a menos que ella constituya por si misma el delito de injuria a particulares".

"No 5: La inviolabilidad del hogar y de toda forma de comunicación privada. El hogar sólo puede allanarse y las comunicaciones y documentos privados interceptarse, abrirse o registrarse en los casos y formas determinados por la ley".

\footnotetext{
${ }^{3}$ Actas de la Comisión Constituyente, $103^{3}$ sesión, de 16 de enero de 1975, pp. 17-18. Sobre los requisitos de un procedimiento justo y racional y el debido proceso ver ALVARADO VELLOSO, Adolfo, "El debido proceso", en Revista Gaceta Juridica N²110, año 1989. CEA EGAÑA, José Luis, Tratado de la Constitución de 1980. Características generales. Garantias constitucionales, Santiago, 1988, pp. 306 quien reproduce las palabras del Sr. Diez, agregando: "...tal imperativo cubriría la publicidad de las actuaciones, el derecho a la acción, el emplazamiento, el examen y objeción de la prueba rendida, la bilateralidad de la audiencia..."; EVANS DE LA CUADRA, Enrique, Los derechos constitucionales, tomo II, Santiago, 1999, tomo II, pp. 143-144 quien expresa que los requisitos para que un procedimiento sea racional y justo son: "1) Notificación y audiencia del afectado, pudiendo procederse en su rebeldia si no comparece una vez notificado; 2) Presentación de las pruebas, recepción de ellas y su examen; 3) Sentencia dictada en un plazo razonable; 4) Sentencia dictada por un tribunal u órgano imparcial y objetivo, y 5) posibilidad de revisión de lo fallado por una instancia superior igualmente imparcial y objetiva"; TAVOLARI OLIVEROS, Raúl, "EI proceso civil chileno: una lectura desde el debido proceso y la eficacia de la jurisdicción de cara a la reforma", en Derecho y Humanidades, año 1992, vol. 12, №2, pp. 151-170 y VERDUGO MARINKOVIC, Mario, PFEFFER URQUIAGA, Emilio y NOGUEIRA ALCALÁ. Humberto, Derecho constitucional, Santiago, 1994, tomo I, p. 223.
} 
La materialización de estas garantías constitucionales se encuentra en los artículos 144 y 146 del Código Penal que sancionan a: "el que entrare en morada ajena contra la voluntad de su morador" y a "el que abriere o registrare la correspondencia de otros"; y en el artículo 161 A se castiga "al que, en recintos particulares o lugares que no sean de libre acceso al público, sin autorización del afectado y por cualquier medio, capte, interprete, grabe o reproduzca conversaciones o comunicaciones de carácter privado; sustraiga, fotografíe, fotocopie o reproduzca documentos o instrumentos de carácter privado; o capte, grabe, filme o fotografíe imágenes de carácter privado que se produzcan, realicen u ocurran o existan en recintos particulares o lugares que no sean de libre acceso al público".

"Igual pena se aplicará a quien difunda las conversaciones, comunicaciones, documentos, instrumentos, imágenes y hechos a que se refiere el inciso anterior".

Las normas del artículo 161 B limita la protección a todo aquello de carácter íntimo o privado que existe u ocurre en recintos particulares o lugares que no sean de libre acceso al público, como una forma de establecer un ámbito preciso de protección, dentro del cual se presume la intención de la persona de mantener o preservar su privacidad e intimidad. Se estima que quien realiza actos de carácter íntimo o privado en lugares públicos, está demostrando que no le interesa la reserva del acto o que renuncia a ella.

De otro lado, las letras c) y d) del artículo 36 B de la Ley de Telecomunicaciones sancionan: "al que intercepte o capte maliciosamente o grabe sin la debida autorización cualquier tipo de señal que se emita a través de un servicio público de telecomunicaciones" y "la difusión pública o privada de cualquier comunicación obtenida con infracción a lo establecido en la letra precedente".

En consecuencia cualquier medida que el Ministerio Público pretenda adoptar y que implique una transgresión a estas normas, deberá ser previamente autorizada por el juez de garantía.

\section{B.- EL DEBIDO PROCESO}

La CPR en el inciso quinto del №3 del artículo 19 establece: "toda sentencia de un órgano que ejerza jurisdicción debe fundarse en un proceso previo legalmente tramitado. Corresponderá al legislador establecer siempre las garantías de un racional y justo procedimiento".

En las actas de la Comisión Constituyente se dejó expresa constancia de que la garantía del "debido proceso " no estaba constreñida al ámbito jurisdiccional sino que a cualquier tipo de procedimiento, incluso respecto de la Administración, pues es ella la 
que de manera más directa puede afectar a las personas. El texto de las actas es el siguiente:

"El señor Evans estima que la expresión 'órgano jurisdiccional' es limitativa, porque hay órganos que no son jurisdiccionales y que, sin embargo, ejercen jurisdicción en casos específicos y para situaciones determinadas".

"Propone decir, en cambio, que: 'Toda sentencia de órgano que ejerza jurisdicción necesita fundarse en un juicio previo legalmente tramitado."

"El señor Diez señala que, en este evento, habría que aclarar que por 'órgano que ejerce jurisdicción' se entiende a los tribunales administrativos, fiscales, Impuestos Internos, Contraloría General de la República, tribunales arbitrales, etcétera. O sea, todo órgano que tenga facultad para dictar una resolución o fallo, llámese como se llame, que afecte la situación de una persona".

"El señor Evans acota que ello significa establecer que la norma se aplicará en toda controversia que se suscite en el orden temporal." 4

Por lo demás, es de esta forma como lo ha entendido la doctrina ${ }^{5}$, la jurisprudencia judicial y la que emana del Tribunal Constitucional $l^{6}$.

Tal como expresara anteriormente, si un afectado o un imputado o un acusado ignora los procedimientos que se han seguido o se están siguiendo en su contra o las razones de tal proceder, le será imposible defender sus derechos. El derecho al conocimiento oportuno de la acción interpuesta y la bilateralidad de la audiencia o

\footnotetext{
${ }^{4}$ Actas Oficiales de la Comisión Constituyente, sesión 193, celebrada en 16 de enero de 1975, pp. 14-15.

${ }^{5}$ CEA EGAÑA, José Luis, (n. 3), p. 304; éste señala: "Y la locución "örgano que ejerza jurisdicción" comprende, desde luego a los tribunales ordinarios y especiales de toda indole y jerarquia, pero también a las autoridades políticas, gubernativas y administrativas - asi como, en su caso por autorización del Estado y con sujeción a los estatutos respectivos, a los representantes de las corporaciones, fundaciones y asociaciones privadas que gozan de personalidad juridica - con facultad legal para conocer acciones litigiosas, comprobar los hechos, subsumirlos en las normas vigentes, decidir la controversia y ordenar la ejecución del respectivo fallo. De manera que la disposición rebasa el marco del Poder Judicial y cubre el área mucho más basta y sustantiva de lo jurisdiccional o definitorio de! Derecho aplicable a la solución de un litigio, es decir, a la representación que de una contienda se hace en un proceso"; EVANS DE LA CUADRA, Enrique, (n. 3), p. 143: "Aclaremos, primero, que se trata de un texto aplicable a cualquier autoridad, expresión sinónima de "órgano" en la Constitución, que ejerza jurisdicción, o sea, que deba cumplir funciones o ejercer atribuciones que afecten derechos de las personas. Además, dejamos establecido que la expresión "sentencia" no se refiere exclusivamente a la sentencia judicial, sino a cualquier resolución, ya vimos que de cualquier autoridad, que ejerciendo sus atribuciones afecte derechos constitucionales - legales"; SOTO KLOSS, Eduardo, El recurso de protección. Orígenes, doctrina y jurisprudencia, Santiago, 1982, p. 115, donde anota: "Hemos señalado cómo el constituyente (sesión 101 cit.) previó que esta garantía del debido proceso también debe tenerse en cuenta referente a la actividad de la Administración".

${ }^{6}$ Ver especialmente las sentencias 8 de septiembre de 1986 , recaída en la Ley $N^{2} 18.556$, publicada el $1^{2}$ de octubre de 1986 (considerandos 21-24) en R.D.J. t. 83, 1986, sec. 620, pp. 93- 98, rol №38; de 4 de enero de 1995 recaida en la Ley $\mathrm{N}^{2} 19.366$, publicada el 20 de enero de 1995 (considerando $10^{2}$ ), rol $\mathrm{N}^{2} 198$.
} 
debido emplazamiento - audiatur altera pars - son un requisito indispensable del "debido proceso".

Es, precisamente, en estos aspectos donde el derecho al justo y racional procedimiento se singulariza en el principio de publicidad de los actos, toda vez que el debido conocimiento de la actuación de los órganos del Estado garantiza una adecuada defensa respecto del incumplimiento de los requisitos de forma y fondo de su actuar.

Así, la actuación del Ministerio Público se encuentra subordinada a este derecho. Tanto es así que, en la discusión de la Reforma Constitucional en el Senado, para evitar toda duda al respecto, se modificó la frase final del inciso $5^{\circ}$ del № 3 del artículo 19 de la CPR, quedando su redacción de la siguiente forma: "Corresponderá al legislador establecer siempre las garantías de un procedimiento y una investigación racionales y justos".

\section{C.- LA LIBERTAD DE EMITIR OPINIÓN Y LA DE INFORMAR, SIN CENSURA PREVIA, EN CUALQUIER FORMA Y POR CUALQUIER MEDIO}

La Constitución, en el número 12 del artículo 19 establece: "La libertad de emitir opinión y la de informar, sin censura previa, en cualquier forma y por cualquier medio, sin perjuicio de responder de los delitos y abusos que se cometan en el ejercicio de estas libertades, en conformidad a la ley".

Esta libertad es indispensable para el mantenimiento y perfeccionamiento de la democracia y del estado de derecho. Como también, la historia nos demuestra el papel fundamental que juega la libertad de expresión y de información en el mantenimiento del estado de derecho, de la dignidad del ser humano, en el combate contra el despotismo, la tiranía y la violación a los derechos de las personas, en el cuidado y exigencia de la probidad en la función pública y, en general y con igual énfasis, para todas las decisiones que diariamente debemos hacer en nuestras distintas actividades. Sin libertad de expresión no hay libertad política ni libertad económica ni libertad espiritual ni libertad cultural.

Esta garantía constitucional no es propia sólo de los medios de comunicación social - como erróneamente se piensa - sino de todas las autoridades y habitantes de la República, sin distinción alguna y conlleva la obligación y la responsabilidad de respetarla irrestrictamente. Esto es, quien la infrinja, sea autoridad o persona jurídica o natural, cualesquiera sea su actividad, incurre en las responsabilidades y sanciones que establece este precepto constitucional.

La propia importancia y los efectos de la libertad de expresión e información obligan a que en su ejercicio se sea doblemente responsable, debido a las serias 
consecuencias que su uso indebido o negligente causa a la sociedad y a las personas en particular. La información para ser tal, debe ser veraz, no tendenciosa, objetiva y pluralista.

Tratándose de delitos y procesos penales, por el enorme daño que se puede causar a una persona y a su familia al darse información falsa, parcial o tendenciosa, en lo que respecta a los medios de comunicación social, es especialmente conveniente tener presente algunos de los siete pecados capitales en que incurren, según el historiador y periodista británico Paul Johnson: "El primero y en algunos aspectos el más importante, es la distorsión" ésta, "deliberada e inadvertida, es mucho más común y puede revertir muchas formas. El tercero, "el hurto de la privacidad". La intrusión en la privacidad, es el pecado más pernicioso de nuestro tiempo en los medios de comunicación y parece estar cundiendo. Cada hombre y mujer mortales tienen un derecho inalienable a algún grado de privacidad. El cuarto, es "el asesinato de la reputación de una persona". Siempre se ha usado a los medios de comunicación para este inescrupuloso propósito. $Y$ el séptimo y último, es una síntesis de todos los anteriores: "el abuso del enorme poder que poseen los medios de comunicación".

\section{LA PUBLICIDAD EN LAS ACTUACIONES DEL MINISTERIO PÚBLICO}

En el caso del Ministerio Público, éste actúa en el sistema procesal penal con dos calidades distintas: una, como ente administrativo en la etapa de investigación. A su vez, en esta etapa cabe diferenciar la diversa situación jurídica que se produce cuando el Ministerio público solicita información a las autoridades y órganos del estado de aquella en que el requerido para proporcionarla es el propio Ministerio Público. La otra, como parte dentro del proceso penal.

\section{A.- COMO ENTE ADMINISTRATIVO EN LA ETAPA DE INVESTIGACIÓN}

1) Naturaleza jurídica de las actuaciones del Ministerio Público

El artículo $80 \mathrm{~A}$ de la CPR establece: "Un organismo autónomo, jerarquizado, con el nombre de Ministerio Público, dirigirá en forma exclusiva la investigación de los hechos constitutivos de delito, los que determinen la participación punible y los que acrediten la inocencia del imputado y, en su caso, ejercerá la acción penal pública en la forma prevista por la ley. De igual manera, le corresponderá la adopción de medidas para proteger a las víctimas y a los testigos. En caso alguno podrá ejercer funciones jurisdiccionales".

En consecuencia, resulta claro que las actuaciones del Ministerio Público son eminentemente administrativas en cuanto a la investigación. Así, por lo demás, se desprende claramente de lo establecido en el inciso $4^{\circ}$ del Art. 8 de la LOC al establecer 
"los actos administrativos del Ministerio Público..." esto es la Ley reconoce expresamente que las actuaciones no procesales del Ministerio Público son de carácter administrativo.

2) Normas que rigen la publicidad en las actuaciones del ministerio público cuando este es requerido para proporcionarla

La Ley Orgánica Constitucional $N^{\circ} 19.640$, en los incisos $2^{\circ}$ y $4^{\circ}$ del Art. $8^{\circ}$ establece:

"La función pública se ejercerá con transparencia, de manera que permita y promueva el conocimiento de los procedimientos, contenidos y fundamentos de las decisiones que se adopten en ejercicio de ella.

Son públicos los actos administrativos del Ministerio Público y los documentos que les sirvan de sustento o complemento directo y esencial. Con todo, se podrá denegar la entrega de documentos o antecedentes requeridos en virtud de las siguientes causales: la reserva o secreto establecidos en disposiciones legales o reglamentarias; cuando la publicidad impida o entorpezca el debido cumplimiento de las funciones del organismo; la oposición deducida por terceros a quienes se refiera o afecte la información contenida en los documentos requeridos; el que la divulgación o entrega de los documentos o antecedentes requeridos afecte sensiblemente los derechos o intereses de terceras personas, según calificación fundada efectuada por el respectivo Fiscal Regional o, en su caso, el Fiscal Nacional, y el que la publicidad afecte la seguridad de la Nación o el interés nacional. El costo del material empleado para entregar la información será siempre de cargo del requirente, salvo las excepciones legales.

La publicidad, divulgación e información de los actos relativos a o relacionados con la investigación, el ejercicio de la acción penal pública y la protección de víctimas y testigos, se regirán por la ley procesal penal".

Conforme a la normativa legal antes transcrita, las actuaciones del Ministerio Público deben regirse por las normas del Código de Procedimiento Penal, tanto en lo administrativo como en su actuación procesal. Sin embargo, el Código de Procedimiento Penal no contiene ninguna norma que reglamente esta materia en lo que respecta al Ministerio Público.

En consecuencia, y aparentemente, sólo habría que atenerse a la normativa antes transcrita que contiene la Ley Orgánica Constitucional, en cuanto señala que los actos administrativos del Ministerio Público y los documentos que le sirvan de sustento - complemento directo y esencial son públicos. Aparte de esta norma genérica, la LOC, establece específicamente aquellos casos en que el Ministerio Público puede negar el 
conocimiento de sus actuaciones y de los documentos, las cuáles son en los siguientes casos:

1) Si se trata de documentos secretos o reservados de conformidad a la ley.

2) Impide o entorpece las funciones del Organismo. Esta es una circunstancia que depende del criterio de la autoridad llamada a calificarla. Es por ello que, si se niega la información requerida, el afectado deberá recurrir a la Jurisdicción. En definitiva, será ésta la que determine la concurrencia o no de esta circunstancia.

3) Si existe oposición deducida por terceros o a quienes se refiere o afecte la información contenida en los documentos.

4) Si la divulgación o entrega de los documentos o antecedentes requeridos afecta sensiblemente los derechos o intereses de terceras personas, según calificación fundada del Fiscal Regional respectivo o, en su caso, del Fiscal Nacional.

5) Si el contenido de un documento afecta a la seguridad de la Nación o el interés nacional.

3) Aplicación de la Ley de Bases de la Administración del Estado

En ausencia de normas que determinen como puede un particular reclamar del Ministerio Público el cumplimiento de la obligación de publicidad que hemos señalado anteriormente, en mi opinión, corresponde aplicar las normas que contiene la LOC de Bases de la Administración Pública, en razón de las siguientes normas legales:

4) LOC 19.640 del Ministerio Público: inciso $1^{\circ}$ del Art. 8:

"Los fiscales y los funcionarios del Ministerio Público deberán observar el principio de probidad administrativa".

5) LOC 18.757 sobre Bases de la Administración del Estado: Arts. 11 bis, incisos $1^{2}, 2^{2}$ y $3^{\circ}$ y $55:$

"Los funcionarios de la Administración del Estado deberán observar el principio de probidad administrativa $y$, en particular, las normas legales generales $y$ especiales que lo regulan".

"La función pública se ejercerá con transparencia, de manera que permita y promueva el conocimiento de los procedimientos, contenidos y fundamentos de las decisiones que se adopten en ejercicio de ella". 
"Son públicos los actos administrativos de los órganos de la Administración del Estado y los documentos que les sirvan de sustento o complemento directo y esencial".

"Artículo 55: El interés general exige el empleo de medios idóneos de diagnóstico, decisión y control, para concretar, dentro del orden jurídico, una gestión eficiente y eficaz. Se expresa en.... Y en el acceso ciudadano a la información administrativa, en conformidad a la ley".

La referencia que la LOC del Ministerio Público hace al principio de probidad administrativa, implica un envío a la normativa que rige esta materia en la LOC de Bases de la Administración del Estado. Si no fuere así, a igual conclusión se llega si se considera que el Ministerio Público no está excluido de la aplicación del Capítulo $3^{\circ}$ de esta LOC, en virtud de lo dispuesto en su Art. 54: "Las autoridades de la Administración del Estado, cualquiera que sea la denominación con que las designen la Constitución y las Leyes, y los funcionarios de la administración pública, sean de planta - a contrata, deberán dar estricto cumplimiento al principio de la probidad administrativa".

Es un axioma indiscutido que el elemento más relevante de la probidad administrativa y consustancial a ella, es el principio de la publicidad. De tal manera que las normas que rigen la aplicación del principio de publicidad en la LOC de Bases Administrativas del Estado se aplican al Ministerio Público en todo aquello que no esté especialmente reglamentado en la LOC del Ministerio Público. Luego, en ausencia de normas especiales, rigen las normas generales de la LOC de Bases Administrativas del Estado.

6) Ejercicio del derecho de terceros para exigir el cumplimiento de la publicidad en las actuaciones del Ministerio Público

Conforme a lo establecido anteriormente, esta materia queda regida por los Art. 11 bis y 11 ter de la LOC 18.575 , cuyo texto es el siguiente:

Artículo 11 bis, incisos $4^{\circ}$ y siguientes: "En caso de que la información referida en los incisos anteriores no se encuentre a disposición del público de modo permanente, el interesado tendrá derecho a requerirla por escrito al jefe del servicio respectivo".

"Cuando el requerimiento se refiera a documentos o antecedentes que contengan información que pueda afectar los derechos o intereses de terceros, el jefe superior del órgano requerido, dentro del plazo de cuarenta y ocho horas, deberá comunicar mediante carta certificada, a la o las personas a que se refiere o afecta la información correspondiente, la facultad que les asiste para oponerse a la entrega de los documentos solicitados, adjuntando copia del requerimiento respectivo". 
"Los terceros interesados podrán ejercer su derecho de oposición dentro del plazo de tres días hábiles contado desde la fecha de notificación, la cual se entenderá practicada al tercer día de despachada la correspondiente carta certificada. La oposición deberá presentarse por escrito y no requerirá expresión de causa".

"Deducida la oposición en tiempo y forma, el órgano requerido quedará impedido de proporcionar la documentación o antecedentes solicitados, salvo resolución judicial en contrario, dictada conforme al procedimiento que establece el artículo siguiente. En caso de no deducirse la oposición, se entenderá que el tercero afectado accede a la publicidad de dicha información, a menos que el jefe superior requerido estime fundadamente que la divulgación de la información involucrada afecta sensiblemente los derechos o intereses de los terceros titulares de la misma".

"El jefe superior del órgano requerido deberá pronunciarse sobre la petición, sea entregando la documentación solicitada o negándose a ello, dentro del plazo de cuarenta y ocho horas contado desde la formulación del requerimiento, o desde la expiración del plazo concedido al tercero afectado, en el caso previsto en el inciso séptimo.

El jefe superior del órgano requerido deberá proporcionar la documentación que se les solicite, salvo que concurra alguna de las causales que establece el inciso siguiente, que le autorizan a negarse. En este caso, su negativa a entregar la documentación deberá formularse por escrito y fundadamente, especificando las razones que en cada caso motiven su decisión".

"Las únicas causales en cuya virtud se podrá denegar la entrega de los documentos o antecedentes requeridos son la reserva o secreto establecidos en disposiciones legales o reglamentarias; el que la publicidad impida o entorpezca el debido cumplimiento de las funciones del órgano requerido; la oposición deducida en tiempo y forma por los terceros a quienes se refiere o afecta la información contenida en los documentos requeridos; el que la divulgación o entrega de los documentos o antecedentes requeridos afecte sensiblemente los derechos o intereses de terceras personas, según calificación fundada efectuada por el jefe superior del órgano requerido, y el que la publicidad afecte la seguridad de la Nación o el interés nacional".

"Uno o más reglamentos establecerán los casos de secreto o reserva de la documentación y antecedentes que obren en poder de los órganos de la Administración del Estado".

Art. 11 ter: "Vencido el plazo previsto en el artículo anterior para la entrega de la documentación requerida, o denegada la petición por una causa distinta de la seguridad de la Nación o el interés nacional, el requirente tendrá derecho a recurrir al juez de letras en lo civil del domicilio del órgano de la Administración requerido, que se 
encuentre de turno según las reglas correspondientes, solicitando amparo al derecho consagrado en el artículo precedente".

"El procedimiento se sujetará a las reglas siguientes:

a) La reclamación deberá señalar claramente la infracción cometida y los hechos que la configuran, y deberá acompañarse de los medios de prueba que los acrediten, en su caso.

b) El tribunal dispondrá que la reclamación sea notificada por cédula, en la oficina de partes de la repartición pública correspondiente y en el domicilio del tercero involucrado, si lo hubiere. En igual forma se notificará la sentencia que se dicte.

c) La autoridad reclamada y el tercero, en su caso, deberán presentar sus descargos dentro de quinto día hábil y adjuntar los medios de prueba que acrediten los hechos en que los fundan. De no disponer de ellos, expresarán esta circunstancia y el tribunal fijará una audiencia, para dentro de quinto día hábil, a fin de recibir la prueba ofrecida y no acompañada.

d) La prueba se consignará en un cuaderno separado y reservado, que conservará ese carácter aun después de afinada la causa, en caso de que por sentencia ejecutoriada se confirmase el carácter secreto o reservado de la información y se denegare el acceso a ella".

"En tanto no exista sentencia ejecutoriada que declare su derecho, en ningún caso el reclamante podrá tener acceso a los documentos objeto del requerimiento, aun cuando fueren acompañados como prueba en el procedimiento que regula este artículo".

“e) La sentencia definitiva se dictará dentro de tercero día de vencido el plazo a que se refiere la letra c) precedente, sea que se hayan o no presentado descargos. Si el tribunal decretó una audiencia de prueba, este plazo correrá una vez vencido el plazo fijado para ésta.

f) Todas las resoluciones, con excepción de la indicada en la letra g) de este inciso, se dictarán en única instancia y se notificarán por el estado diario.

g) La sentencia definitiva será apelable en ambos efectos. El recurso deberá interponerse en el término fatal de cinco días, contado desde la notificación de la parte que lo entabla, deberá contener los fundamentos de hecho y de derecho en que se apoya y las peticiones concretas que se formulan.

h) Deducida la apelación, el tribunal elevará de inmediato los autos a la Corte de Apelaciones respectiva. Recibidos los autos en la Secretaría de la Corte, el Presidente 
ordenará dar cuenta preferente del recurso, sin esperar la comparecencia de ninguna de las partes.

i) El fallo que se pronuncie sobre la apelación no será susceptible de los recursos de casación".

"En caso de que la causal invocada para denegar la entrega de documentos o información fuere el que su publicidad afecta la seguridad de la Nación o el interés nacional, la reclamación del requirente deberá deducirse ante la Corte Suprema, la que solicitará informe de la autoridad de que se trate por la vía que considere más rápida, fijándole plazo al efecto, transcurrido el cual resolverá en cuenta la controversia. En caso de ser pertinente, será aplicable en este caso lo dispuesto en la letra d) del inciso anterior".

"La sala de la Corte Suprema que conozca la reclamación conforme al inciso anterior, o la sala de la Corte de Apelaciones que conozca la apelación, tratándose del procedimiento establecido en los incisos primero y segundo, si lo estima conveniente o se le solicita con fundamento plausible, podrá ordenar traer los autos en relación para oír a los abogados de las partes, en cuyo caso la causa se agregará extraordinariamente a la tabla respectiva de la misma Sala. En estos casos, el Presidente del Tribunal dispondrá que la audiencia no sea pública".

"En caso de acogerse la reclamación, la misma sentencia que ordene entregar los documentos o antecedentes fijará un plazo prudencial para ello. En la misma resolución, el tribunal podrá aplicar al jefe del servicio una multa de dos a diez unidades tributarias mensuales".

"La no entrega oportuna de los documentos o antecedentes respectivos, en la forma que decrete el tribunal, será sancionada con la suspensión del jefe del servicio de su cargo, por un lapso de cinco a quince días, y con multa de dos a diez unidades tributarias mensuales. Si el jefe del servicio persistiere en su actitud, se le aplicará el duplo de las sanciones indicadas".

"El costo del material empleado para entregar la información será siempre de cargo del requirente, salvo las excepciones legales".

La claridad de los preceptos legales sólo hace necesario destacar que en el artículo 11 ter se contemplan dos procedimientos, según que la información requerida se deniegue por cualquier causa que no sea vulnerar la seguridad de la Nación o el interés nacional o que se aduzca la seguridad de la Nación o el interés nacional.

La principal diferencia entre ambos procedimientos estriba en el tribunal encargado de conocer la reclamación. En el primer caso, es competente para conocer 
de ella el juez letrado en lo civil del domicilio del órgano de la administración requerido. Esta norma debiera interpretarse en el sentido de que se trata del domicilio de la oficina administrativa que denegó el acceso, única manera de que se cumpla la finalidad de la norma y no se obligue al requeriente a recurrir a un tribunal de Santiago, con la consiguiente pérdida de tiempo y costo pecuniario que ello implica.

En el segundo, es la Corte Suprema de Justicia.

a) Es del caso destacar las siguientes normas comunes a ambos procedimientos:

La prueba se consignará en un cuaderno separado y reservado, que conservará ese carácter aun después de afinada la causa, en caso de que por sentencia ejecutoriada se confirmase el carácter secreto o reservado de la información y se denegare el acceso a ella.

b) En tanto no exista sentencia ejecutoriada que declare su derecho, en ningún caso el reclamante podrá tener acceso a los documentos objeto del requerimiento, aun cuando fueren acompañados como prueba en el procedimiento que regula este artículo.

c) La Sentencia, en caso de acoger la reclamación, fijará un plazo prudencial para entregar los documentos o antecedentes. Además, en la misma resolución, el tribunal podrá aplicar al jefe del servicio una multa de dos a diez unidades tributarias mensuales.

d) La no entrega oportuna de los documentos o antecedentes respectivos, en la forma que decrete el tribunal, será sancionada con la suspensión de su cargo del jefe del servicio, por un lapso de cinco a quince días, y con una multa de dos a diez unidades tributarias mensuales. En el caso de que, aplicadas estas sanciones, el jefe del servicio insistiere en no cumplir con la orden judicial, se le aplicará el duplo de las sanciones ya indicadas.

7) Normas que se aplican cuando el Ministerio Público es el que solicita la información

Esta materia está reglamentada en el Art. 19 del CPP, y se refiere al caso de que el fiscal o un tribunal con competencia penal hayan requerido información a una autoridad u órgano del Estado y éste se la haya negado.

Al igual que en el caso anterior, hay que distinguir cual es la razón que motiva el rechazo para determinar el Tribunal encargado de resolver el conflicto. Si la autoridad requerida retardare el envío de los antecedentes solicitados o se negare a enviarlos, con el pretexto de su carácter secreto o reservado y el Fiscal estimare indispensable la realización de la actuación, remitirá los antecedentes al Fiscal Regional quien, si compartiere esa apreciación solicitará a la Corte de Apelaciones respectiva que, previo 
informe de la autoridad de que se tratare, recabado por la vía que considere más rápida, resuelva la controversia.

Si la razón invocada por la autoridad requerida para no enviar los antecedentes solicitados fuere que su publicidad pudiere afectar la seguridad nacional, la cuestión deberá ser resuelta por la Corte Suprema.

\section{B.- ACTUACIÓN DEL MINISTERIO PÚBLICO COMO PARTE EN EL PROCESO PENAL}

El Ministerio Público es simplemente una parte en el proceso penal y sus actuaciones se rigen, al igual que la de "cualquier otro interviniente" por las normas establecidas en los Arts. 44 y 289 del Código de Procedimiento Penal, que se analizan en el capítulo siguiente.

1) Procedencia al Recurso de protección para reclamar de la infracción en que pueda incurrir el Ministerio Público al principio de publicidad

Además de la reclamación analizada anteriormente, en opinión del autor, es posible deducir un recurso de protección en caso de que se niegue el acceso a la información y ello constituya una acción u omisión ilegal o arbitraria. Esto, en razón de que el principio de publicidad es un elemento fundamental para materializar la garantía constitucional a un debido proceso e investigación.

Se ha sostenido esta acción de protección no procede respecto el inciso $5^{\circ}$ del № 3 del artículo 19, que es la norma constitucional que establece la garantía del "debido proceso e investigación". No obstante ello, existen opiniones y jurisprudencia que afirman lo contrario, en base a lo siguiente:

a) La garantía al justo y racional procedimiento e investigación se encuentra amparada por la garantía del № 2 del artículo 19.

La garantía que consagra el $N^{\circ} 3$ del artículo 19 de la CPR; la igual protección en el ejercicio de los derechos - nace necesariamente de la garantía de igualdad ante la ley y así lo consideró la Comisión Ortúzar. La doctrina, desde siempre, ha sostenido que entre ambas garantías hay una relación de género a especie. Entonces, si la igualdad ante la ley se encuentra dentro de los derechos protegidos por el recurso de protección, como corolario de ello, toda la garantía "de igual protección a los derechos" estaría amparada por esta acción.

Así lo sostuvo la sentencia de la Corte de Apelaciones de Temuco, de 15 de diciembre de 1987, recaída en el recurso de protección entablado por Miguel Ángel Villarroel Villarroel, en representación de "Ingeniería y Construcciones Civem Ltda.", 
en contra del Contralor Regional de la Araucanía, sentencia que fue confirmada por la Corte Suprema el 26 de noviembre de $1988^{7}$.

Otro ejemplo está en el recurso interpuesto por Víctor Hugo Painemal Arriagada y Oscar López López en contra del Director Nacional de Desarrollo Indígena y el Fiscal de la misma corporación en el año $1996^{8}$.

b) La garantía al justo y racional procedimiento e investigación se encuentra amparada por la garantía del inciso $4^{\circ}$ del № 3 del artículo 19.

Esta norma establece el llamado "derecho al juez natural", vale decir, prohíbe que las personas sean juzgadas por "comisiones especiales". La doctrina señala que nos encontramos frente a comisiones especiales no sólo cuando el órgano que juzga ha sido establecido por la ley con anterioridad a la iniciación del proceso, sino que también cuando carece de los requisitos mínimos para decidir sobre situaciones jurídicas de terceros, vale decir, carece de la independencia e imparcialidad necesarias para emitir su pronunciamiento, incumpliendo, con ello, las reglas básicas de todo procedimiento e investigación justo y racional ${ }^{9}$.

En consecuencia, si un fiscal o un tribunal vulnera las garantías mínimas de un debido procedimiento pasa a ser considerado una "comisión especial" de conformidad a

\footnotetext{
${ }^{7}$ R.D.J. t. LXXXV, $2^{2}$ parte, secc. $5^{2}$, pp. 67-72.

${ }^{8}$ F. M. N2 465, agosto de 1997 , p. 1308.

${ }^{9}$ De esta manera lo ha señalado SOTO KLOSS, Eduardo: "Pues bien, esta garantía de 'no ser juzgado por comisiones especiales', no cabe interpretarla de manera tan estrecha, como creemos se ha hecho en el fallo citado, reduciéndola a una sola de sus facetas, sino debe entenderse en toda la amplitud que de suyo ella implica, haciéndola jugar cada vez que quien decide sobre situaciones de terceros - en cuanto órgano habilitado para ello por la Constitución o las leyes- afectando sus situaciones jurídicas, carece de los requisitos más mínimos para juzgar (o sea decidir respecto de hechos, conductas o comportamientos de esos terceros) por carecer de la independencia e imparcialidad requeridas para desempeñar esa función. Y es que el carecer un órgano de esos atributos lo convierte ipso facto en una 'comisión especial', y. por ende, queda legitimado el afectado para recurrir de protección en amparo de sus derechos, pues derecho fundamental - reconocido por el constituyente y protegido procesalmente en su legítimo ejercicio- es que 'nadie puede ser juzgado por comisiones especiales'". SOTO KLOSS, Eduardo, (n. 5), p. 115. Esta misma idea la ha reiterado al señalar “... lo cierto es que los incisos $5^{\circ}$ y $4^{\circ}$ referidos están absolutamente indisolublemente unidos -como ya lo señaláramos en nuestro El recurso de protección pp. 113-116 ya que violado el inciso $5^{\circ}$ quien lo viola deja de ser juez natural del asunto que conoce transformándose en comisión especial (inciso $4^{\circ}$ ) y por ende cae en inconstitucionalidad", SOTO KLOSS, Eduardo, en comentario a Rozas Diaz, Luis Ángel y otros con Director de la Policía de Investigaciones de Chile, en R.D.J., t. LXXXVIII, $2^{3}$ parte, sec. 5\%, p. 133.

La misma idea han expuesto Mario Verdugo, Emilio Pfeffer y Humberto Nogueira: "Como lo ha dicho nuestro Tribunal Constitucional, 'todo juzgamiento debe emanar de un órgano objetivamente independiente $y$ subjetivamente imparcial, creado por la ley. Es más, se ha reiterado que la independencia e imparcialidad del juez no sólo son componentes de todo proceso justo y racional, sino que, además, son elementos consustanciales al concepto mismo de tribunal'", VERDUGO MARINKOVIC, Mario, PFEFFER URQUIAGA, Emilio y NOGUEIRA ALCALÁ, Humberto, (n. 3), tomo I, p. 220.
} 
lo expuesto por nuestra doctrina, lo que se ha visto reiterado por la jurisprudencia. La Corte Suprema, en diversas recursos de protección, ha acogido esta tesis.

Uno de los primeros casos fue el de Isidro Gómez Chamorro con el Ministro de Salud en el año $1985^{10}$.

En el mismo sentido, en el año 1990 encontramos un recurso interpuesto por funcionarios exonerados de la Policía de Investigaciones de Chile contra el Director General de la Policía de Investigaciones de Chile y el Ministro de Defensa ${ }^{11}$.

c) La praxis judicial.

Si bien en un principio la jurisprudencia no aceptó proteger la garantía del debido proceso mediante el recurso de protección, desde hace algún tiempo observamos que la práctica judicial ha impuesto que siempre la violación a esta garantía implica, al menos, un fundamento en el cual es válido apoyarse tanto al fundamentar el recurso como para la dictación de la sentencia.

Además de las sentencias citadas anteriormente, existen otras en las cuales se sostiene el mismo principio, como ser:

- Recurso de protección interpuesto por doña Margarita Haydeé Chacón Silva en contra del Gobernador de la Provincia de Arauco en $1994^{12}$.

- Recurso interpuesto por Pesquera Mar del Sur S.A. en contra del Ministro de Economía, Fomento y Reconstrucción en el año $1996^{13}$.

Lo anterior demuestra que la falta de un debido proceso ha permitido a los tribunales acoger recursos de protección cuando esta circunstancia ha quedado de manifiesto en el recurso de protección entablado. En materia de investigación, para ejercer el derecho a la defensa y para que realmente exista una debida investigación, se requiere de la debida materialización del principio de publicidad. En consecuencia, la falta de observancia de estos principios importa una violación a la garantía del debido proceso e investigación $y$, por ello, sería posible acoger un recurso de protección fundado en estas circunstancias.

\footnotetext{
${ }^{10}$ R.D.J.t. $L X X X 11,2^{2}$ parte, secc. $5^{2}$, p. 296.

${ }^{11}$ R.D.J.t. LXXXVIII, $2^{3}$ parte, secc. $5^{2}$, p. 123

${ }^{12}$ G. J. N² 173, noviembre del año 1994, p. 78.

${ }^{13}$ F. M. N2 461, abril de 1997, p. 269.
} 


\section{LA PUBLICIDAD EN LA ACTUACIÓN DE LOS JUZGADOS DE GARANTÍA Y ANTE EL TRIBUNAL ORAL EN LO PENAL}

\section{A.- LA REgLa genERAL PARA LOS JUZGAdOS DE GARANTías SE ENCUENTRA ESTABLECIDA EN EL ARTÍCULO 44 DEL CÓDIGO DE PROCEDIMIENTO PENAL QUE ESTABLECE:}

"Salvas las excepciones expresamente previstas en la ley, los intervinientes siempre tendrán acceso al contenido de los registros".

"Los registros podrán también ser consultados por terceros cuando dieren cuenta de actuaciones que fueren públicas de acuerdo con la ley, a menos que, durante la investigación o la tramitación de la causa, el tribunal restringiere el acceso para evitar que se afecte su normal substanciación o el principio de inocencia".

"En todo caso, los registros serán públicos transcurridos cinco años desde la realización de las actuaciones consignadas en ellos".

"A petición de un interviniente o de cualquier persona, el funcionario competente del tribunal expedirá copias fieles de los registros o de la parte de ellos que fuere pertinente, con sujeción a lo dispuesto en los incisos anteriores".

En consecuencia, en este artículo se distingue la publicidad respecto de los intervinientes y respecto de terceros.

\section{1) Respecto de los intervinientes}

La única limitación al principio de publicidad que se establece respecto de los intervinientes es por causal establecida en la ley, sin perjuicio de que transcurridos 5 años, toda la información contenida en los registros pasará a ser pública.

\section{2) Respecto de terceros}

- Si es un tercero quien desea consultar un registro es menester que:

a) Se trate de una actuación que de acuerdo a la ley sea pública.

b) Que el tribunal durante la investigación o la tramitación de la causa no hubiera restringido el acceso al registro, a fin de evitar dos circunstancias:

- Afectar la normal sustanciación.

- Afectar el principio de inocencia. 
En todo caso, al igual que en el caso de los intervinientes, los registros serán públicos una vez transcurridos 5 años desde la realización de las actuaciones consignadas en ellos.

\section{B.- LA PUBLICIDAD DE LAS ACTUACIONES ANTE EL TRIBUNAL ORAL EN LO PENAL, SE REGULA EN EL ARTÍCULO 289 DEL CODIGO DE PROCEDIMIENTO PENAL, QUE ESTABLECE:}

"La audiencia del juicio oral será pública, pero el tribunal podrá disponer, a petición de parte y por resolución fundada, una o más de las siguientes medidas, cuando considerare que ellas resultan necesarias para proteger la intimidad, el honor o la seguridad de cualquier persona que debiere tomar parte en el juicio o para evitar la divulgación de un secreto protegido por la ley:

a) Impedir el acceso u ordenar la salida de personas determinadas de la sala donde se efectuare la audiencia;

b) Impedir el acceso del público en general u ordenar su salida para la práctica de pruebas específicas, $y$

c) Prohibir al fiscal, a los demás intervinientes y a sus abogados que entreguen información o formulen declaraciones a los medios de comunicación social durante el desarrollo del juicio.

"Los medios de comunicación social podrán fotografiar, filmar o transmitir alguna parte de la audiencia que el tribunal determinare, salvo que las partes se opusieren a ello. Si sólo alguno de los intervinientes se opusiere, el tribunal resolverá".

En consecuencia, la regla general es que las actuaciones realizadas ante el tribunal oral en lo penal son públicas, salvo que se den los siguientes requisitos copulativos:

a) Exista solicitud de alguno de los intervinientes.

b) El tribunal aceda por resolución fundada.

c) El tribunal deberá dictar alguna de las medidas que establece la disposición, vale decir:

d) Impedir el acceso u ordenar la salida de personas determinadas de la sala donde se efectuare la audiencia.

e) Impedir el acceso del público en general u ordenar su salida para la práctica de pruebas específicas. 
f) Prohibir al fiscal, a los demás intervinientes y a sus abogados que entreguen información o formulen declaraciones a los medios de comunicación social durante el desarrollo del juicio.

g) Las medidas resulten necesarias para proteger la intimidad, el honor o la seguridad de cualquier persona que debiere tomar parte en el juicio o para evitar la divulgación de un secreto protegido por la ley.

En el caso de que se infringieren las normas sobre publicidad, el artículo 294 del Código de Procedimiento Penal establece: "Quienes infringieren las medidas sobre publicidad previstas en el artículo $289 \ldots$ podrán ser sancionados de conformidad con los artículos 530 ó 532 del Código Orgánico de Tribunales, según correspondiere".

Todo ello, sin perjuicio de que el tribunal podrá expulsar a los infractores de la sala. Si el expulsado fuere el fiscal o el defensor, deberá procederse a su reemplazo antes de continuar el juicio. Si lo fuere el querellante, se procederá en su ausencia y si lo fuere su abogado, deberá reemplazarlo.

Además de las sanciones disciplinarias, el artículo 374 estableció la sanción de nulidad del juicio o la sentencia si: "d) Cuando en el juicio oral hubieren sido violadas las disposiciones establecidas por la ley sobre publicidad y continuidad del juicio".

\section{V.- CONSIDERACIONES FINALES}

Finalmente, cabe señalar que toda información que dé el Ministerio Público respecto de la investigación y de su actuación en el proceso, debe estar regida por los principios que informa la garantía constitucional contemplada en el №4 del Art. 19 en concordancia con el № 12 del mismo artículo de la CPR, lo que está reiterado en el Art. $8^{\circ}$ de la LOC del Ministerio Público en cuanto faculta a este organismo para denegar la entrega de documentos $\bigcirc$ antecedentes requeridos si su divulgación afecta sensiblemente los derechos o intereses de terceras personas.

La vulneración a esta obligación al igual como ocurre con los medios de comunicación social, hace aplicable al Ministerio Público la normativa constitucional en cuanto a la responsabilidad y sanción consiguiente. En este sentido, cabe reiterar que el № 12 del Art. 19 de la CPR, no sólo obliga a responder por los delitos, sino también por los abusos que se cometan en el ejercicio de la libertad de emitir opinión y de informar, sin censura previa, en cualquier forma y por cualquier medio.

Santiago, noviembre de 2000 